02

\title{
Эффекты близости и Джозефсона в бислоях из нитрида ниобия и алюминия
}

\author{
(С) М.Ю. Левичев ${ }^{1}$, А.И. Елькина ${ }^{1}$, Н.Н. Бухаров ${ }^{2}$, Ю.В. Петров ${ }^{3}$, А.Ю. Аладышкин ${ }^{1,4}$, \\ Д.Ю. Водолазов ${ }^{1}$, А.М. Клушин ${ }^{1, \uparrow}$
}

${ }^{1}$ Институт фризики микроструктур РАН,

Нижний Новгород, Россия

${ }^{2}$ Нижегородское научно-производственное объединение им. М.В. Фрунзе,

Нижний Новгород, Россия

${ }^{3}$ Санкт-Петербургский государственный университет,

Санкт-Петербург, Россия

${ }^{4}$ Нижегородский государственный университет им. Н.И. Лобачевского,

Нижний Новгород, Россия

IE-mail: a_klushin@ipmras.ru

Поступила в Редакцию 15 апреля 2019 г.

В окончательной редакции 22 апреля 2019 г.

Принята к публикации 24 апреля 2019 г.

Исследованы сильно разупорядоченные тонкие пленки из нитрида ниобия и особенности проявления эффекта близости в бислоях $\mathrm{NbN}(\mathrm{S})$-алюминий $(\mathrm{N})$ с большим соотношением их удельных сопротивлений $\rho_{\mathrm{NbN}} / \rho_{\mathrm{Al}} \gg 1$. Показано, что магнитное экранирование и критический ток $I_{c}$ таких $\mathrm{SN}$ структур значительно возрастают по сравнению с $\mathrm{S}$ слоем. Наблюдаемый эффект связан с возникновением наведенной сверхпроводимости в $\mathrm{N}$ слое за счет эффекта близости. Продемонстрирован эффект Джозефсона в мостиках переменной толщины $\mathrm{NbN} / \mathrm{Al}-\mathrm{NbN}-\mathrm{NbN} / \mathrm{Al}$, изготовленных из таких $\mathrm{SN}$ бислоев.

Ключевые слова: сверхпроводимость, эффект близости, эффект Джозефсона, джозефсоновские контакты.

DOI: 10.21883/FTT.2019.09.48095.24N

\section{1. Введение}

В недавней работе [1] теоретически и экспериментально изучался эффекта близости в бислоях из нормального металла $\mathrm{N}$ с малым удельным сопротивлением $\rho_{\mathrm{N}}$, осажденного на поверхность сверхпроводника $\mathrm{S}$ с большим удельным сопротивлением $\rho_{\mathrm{S}}$ в нормальном состоянии (рис. 1). Было показано существенное увеличение экранирующих свойств $\Lambda^{-1}$ всего $\mathrm{SN}$ бислоя из материалов с $\rho_{\mathrm{S}} / \rho_{\mathrm{N}} \gg 1$ по сравнению с $\lambda$, глубиной проникновения магнитного поля одиночной сверхпроводящей пленки. Также было наблюдено значительное возрастание критического тока мостика $I_{c \mathrm{SN}}$ по сравнению с критическим

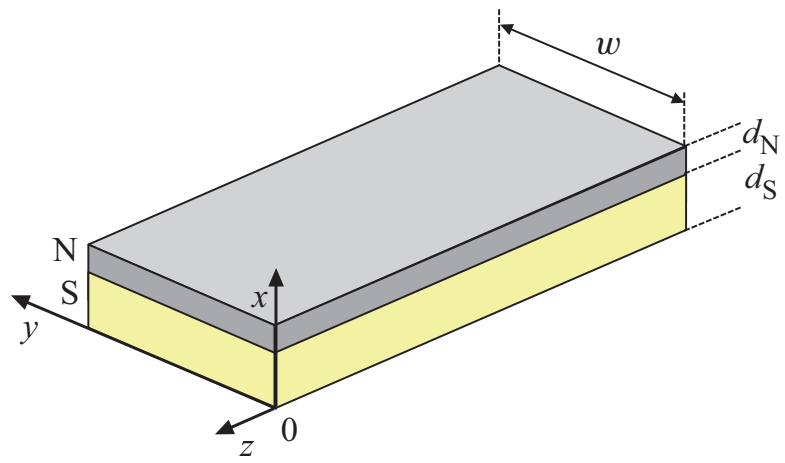

Рис. 1. Схематическое изображение SN бислоя.

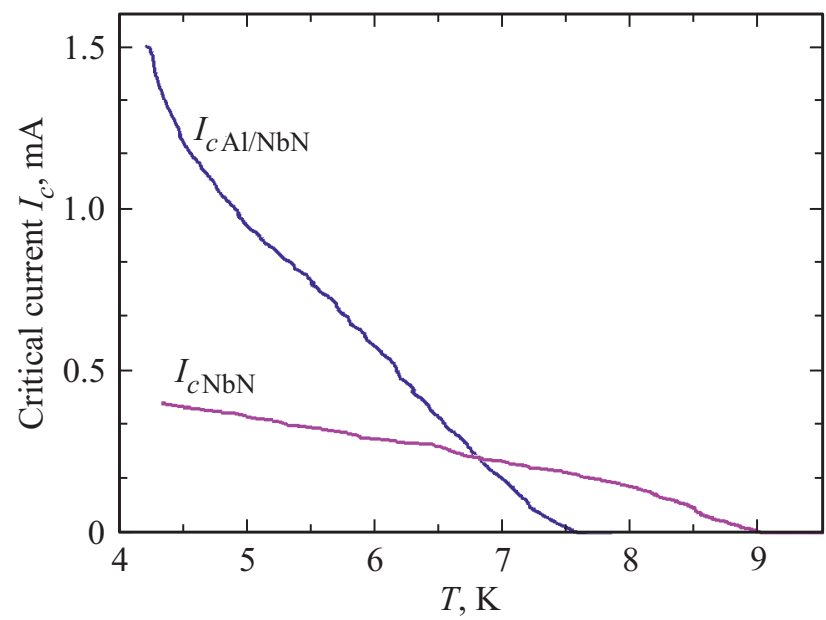

Рис. 2. Зависимость от температуры критического тока $I_{c \mathrm{NbN}}$ мостика шириной $4 \mu \mathrm{m}$ из $\mathrm{NbN}$ толщиной $17 \mathrm{~nm}$ и критического тока $I_{c \mathrm{NbN} / \mathrm{Al}}$ бислоя NbN/Al с толщиной алюминия $34 \mathrm{~nm}$.

током мостика $I_{c}$, изготовленного из этого сверхпроводника (рис. 2) с понижением температуры. Указанные эффекты были предсказаны и наблюдались в широком интервале температур в SN структурах, изготовленных из тонких пленок $\mathrm{N}$ и $\mathrm{S}$ металлов с толщинами $d_{\mathrm{N}}$ и $d_{\mathrm{S}}$ равными или менее $2 \xi_{\mathrm{S}}$. Здесь $\xi_{\mathrm{S}}=\sqrt{h D_{\mathrm{S}} / k_{B} T_{0}}$ длина когерентности в $\mathrm{S}$ пленках, $D_{\mathrm{S}}$ - коэффициент диффузии, 
a $T_{c 0}$ - критическая температура $\mathrm{S}$ пленки в нулевом магнитном поле при отсутствии эффекта близости.

В статье обсуждаются свойства таких структур из тонких пленок нитрида ниобия и алюминия, а также представлены первые результаты по исследованию в постоянном магнитном и СВЧ полях планарных мостиков переменной толщины (МПТ), в которых перемычка длиной $L \approx 20 \mathrm{~nm}$ изготавливалась из сверхпроводника $\mathrm{NbN}$, а берега из бислоя $\mathrm{NbN} / \mathrm{Al}$.

\section{2. Эффект близости в бислоях $\mathrm{NbN} / \mathrm{Al}$}

Бислои $\mathrm{NbN} / \mathrm{Al}$ изготавливались в высоковакуумной установке с остаточным давлением менее $10^{-7} \mathrm{mbar}$ на сапфировых подложках размером $10 \times 10 \mathrm{~mm}^{-2}$, находящихся при комнатной температуре. Напыление $\mathrm{NbN}$ и Al проходило в одном вакуумной цикле. Тонкие пленки $\mathrm{NbN}$ формировались путем магнетронного распыления на постоянном токе ниобиевой мишени в смеси газов $\operatorname{Ar}(99.999 \%)$ и $\mathrm{N} 2 \quad(99.999 \%)$ при давлении $7 \times 10^{-3}$ mbar. Скорость осаждения слоев $\mathrm{NbN}$ была равна $1.3 \mathrm{~nm} / \mathrm{s}$. Пленки $\mathrm{Al}$ напылялись методом магнетронного распыления на переменном токе в атмосфере $\mathrm{Ar}$ при давлении $2 \times 10^{-2}$ mbar. Скорость осаждения слоев $\mathrm{Al}$ изменялась в диапазоне от 1 до $3 \mathrm{~nm} / \mathrm{s}$. В дальнейшем будут представлены результаты исследования образца $\mathrm{RDE} 458$ с толщинами пленок $\mathrm{NbN}$ и $\mathrm{Al}$ равными примерно 15 и $29 \mathrm{~nm}$, соответственно.

Для определения критической температуры и диамагнитного отклика SN слоев мы размещали образец между двумя катушками и измеряли взаимную индуктивность $M$ между ними в зависимости от температуры в интервале от 300 до $4.2 \mathrm{~K}$ [2]. Установка для измерения экранирующих свойств сверхпроводящих пленок в магнитном поле состоит из: криогенного зонда-вставки в транспортный сосуд дьюара СТГ-40, генератора синусоидального сигнала и синхронного детектора SR-830 с измерительным трансформатором SR554 с коэффициентом трансформации 1:100; источника тока для сверхпроводящего магнита СТС-60; а также контроллера температуры Scientific Instruments M9700. В криогенном зонде смонтирована измерительная головка, состоящая из двух медных пластин, в каждой из которых установлены катушки индуктивности диаметром 7 и высотой $6 \mathrm{~mm}$. На одной из пластин установлен термометр и сделано углубление $10 \times 10 \times 0.7 \mathrm{~mm}$ над центром катушки, в которое устанавливается измеряемый образец. Вторая пластина прикручивается к первой двумя винтами так, что катушки оказываются соосны и образец находится между ними. К входной катушке через аттенюатор подключен генератор, а вторая приемная через трансформатор подключена ко входу синхронного детектора. Уровень сигнала на входной катушке выбирается таким, чтобы критическая температура не менялась при изменении уровня входного сигнала. При переходе образца в сверхпроводящее состояние в

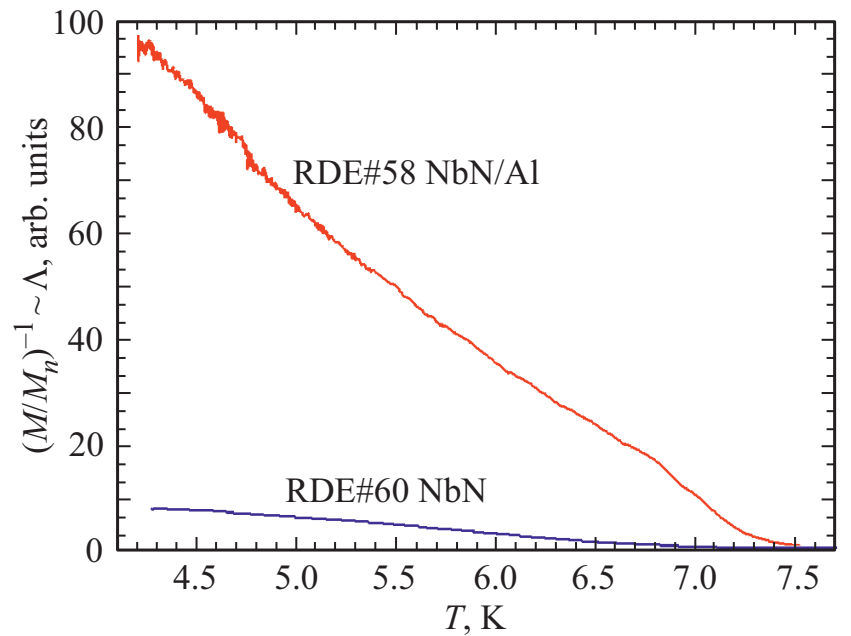

Рис. 3. Температурная зависимость нормированной взаимной индукции $\left(M / M_{n}\right)^{-1} \sim \Lambda$ для бислоя NbN/Al с толщинами $d_{\mathrm{NbN}}=15 \mathrm{~nm}$ и $d_{\mathrm{Al}}=29 \mathrm{~nm}$, а также пленки $\mathrm{NbN}$ с $d_{\mathrm{NbN}}=13.5 \mathrm{~nm} . M_{n}-$ взаимная индукция при температуре незначительно выше $T_{c}$.

результате экранировки сигнал на приемной катушке падает. Однако на толстых сверхпроводящих пленках было обнаружено, что после падения сигнала примерно в 200 раз он выходит на константу. Так же этот остаточный сигнал виден, если разнести приемную и передающую катушку далеко друг от друга. Уровень паразитного сигнала определяется наводкой через провода. Было также обнаружено, что при подключении входной катушки без трансформатора, уровень наводки примерно в 500 раз меньше начального уровня сигнала. Однако в этом случае хуже отношение сигнал-шум, и приходится добавлять уровень входного сигнала от генератора по мере падения принимаемого сигнала для снятия характеристик с малым шумом и в тоже время избежать индукционного разогрева образца вблизи критической температуры. Фаза полезного сигнала и фаза наводки как правило отличаются и в эксперименте, когда сигнал становится меньше наводки изменяется фаза принимаемого сигнала.

В нашем случае можно считать, что при $T<T_{c}$ обратная величина взаимной индукции $M^{-1} \sim \Lambda$. На рис. 3 приведены температурные зависимости обратной величины нормированной взаимной индукции $\left(M / M_{n}\right)^{-1} \sim \Lambda$ для бислоя $\mathrm{NbN} / \mathrm{Al}$, а также пленки $\mathrm{NbN}$. Здесь $M_{n}-$ взаимная индукция при температуре немного выше $T_{c}$. Толщина пленки $\mathrm{NbN}$ была равна $d_{\mathrm{NbN}}=15 \mathrm{~nm}$, то есть равнялась примерно $2 \xi_{\mathrm{NbN}}$ в этом материале [3]. Значительное увеличение эффекта экранирования в бислое $\mathrm{NbN} / \mathrm{Al}$ по сравнению с тонкой пленкой $\mathrm{NbN}$ свидетельствует о сильном эффекте близости в исследованной структуре. 


\section{3. Эффект Джозефсона в бислоях $\mathrm{NbN} / \mathrm{Al}$}

Эффект Джозефсона в двухслойных структурах нормальный металл - сверхпроводник ранее активно исследовался в мостиках переменной толщины типа $\mathrm{SN}-\mathrm{N}-\mathrm{SN}$, предложенных в работе [3]. В этих МПТ (VTB - variable thickness bridge) в качестве материала мостика использовался нормальный металл, а берега формировались из сверхпроводника либо легкоплавкого типа Sn [4], либо тугоплавкого типа Nb [5]. Принципиальным условием наблюдения эффекта Джозефсона в таких структурах является наличие эффекта близости между слоями нормального металла и напыленного поверх него слоя сверхпроводника. Следует отметить, что тонкие пленки сверхпроводника ранее использовались в качестве материалов для изготовления мостиков. Например, в работе [6] изучались мостики из $\mathrm{Nb}$. Более того, для уменьшения перегрева мостиков на берега из $\mathrm{Nb}$ наносились пленки золота. Однако бислоях $\mathrm{Nb}$ и $\mathrm{Au}$ не наблюдался эффект близости и преимущества МПТ реализовать не удалось.

Ниже будут представлены результаты исследования мостиков переменной толщины (рис. 4) типа NS-S-NS, в которых в качестве материала мостика используется сверхпроводник $\mathrm{NbN}$, а берега мостика изготовлены из бислоя NbN/Al. Для наблюдения эффекта Джозефсона мы изготавливали сначала $\mathrm{SN}$ мостики из бислоя шириной $w$ от 3 до $50 \mu \mathrm{m}$. Мостики формировались методом ионного травления $\mathrm{Al}$ и $\mathrm{NbN}$ ионами $\mathrm{Ar}^{+}$в установке Plasmalab 80 plus (Oxford Instruments), оснащенной источниками емкостной (HF) и индуктивной (ICP) плазмы. Затем в этих мостиках были изготовлены поперечные „канавки““ шириной от 10 до $30 \mathrm{~nm}$, в которых был полностью или частично удален верхний слой Al. Таким образом были созданы мостики переменной толщины типа $\mathrm{NbN} / \mathrm{Al}-\mathrm{NbN}-\mathrm{NbN} / \mathrm{Al}$.

Джозефсоновский переход на основе структур NbN/Al формировался локальным удалением верхнего слоя алюминия путем распыления области размером $L$ сфокусированным пучком ионов гелия $\mathrm{He}^{+}$. Распыление выполнялось с помощью гелиевого ионного микроскопа Carl Zeiss Orion, оборудованного литографической системой Nanomaker, при энергии ионов $35 \mathrm{keV}$ и токе пучка около 3 пА. Облучаемая структура представляла собой прямоугольную полосу ориентированную перпендикулярно предварительно сформированному мостику. Ширина прямоугольных полос составляла 5,15 и $25 \mathrm{~nm}$. Облучение производилось растровым заполнением структуры с шагом между точками $1 \mathrm{~nm}$. Время воздействия в одной точке соответствовало дозе порядка $10^{19} \mathrm{~cm}^{-2}$. Для точного определения дозы, необходимой для распыления, проводились предварительные оценки скорости распыления двухслойной структуры. На первом этапе определялась доза, необходимая для полного удаления структуры с сапфировой подложки. Необходимо отметить, что полученные значения дозы зависели от ширины

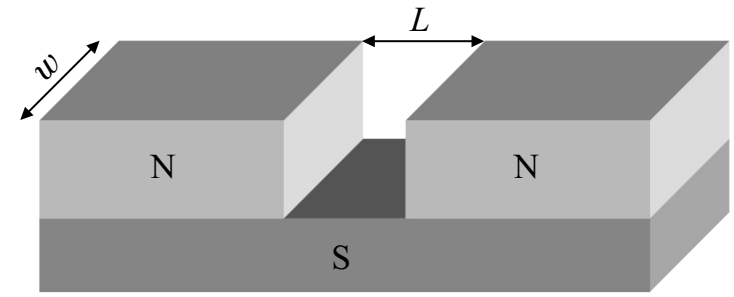

Рис. 4. Схематическое изображение мостика переменной толщины шириной $w$ и длиной $L$, в котором в качестве материала мостика $\mathrm{S}$ используется сверхпроводник $\mathrm{NbN}$, а берега мостика изготовлены из $\mathrm{SN}$ бислоя $\mathrm{NbN} / \mathrm{Al}$.

облучаемой полосы, поскольку размеры области рассеяния ионов гелия в веществе при используемой энергии превышают ширину облучаемой области более чем на порядок. Затем оценивалось время необходимое для удаления верхнего слоя алюминия. При этом учитывалось отношение коэффициентов распыления алюминия и нитрида ниобия, которое, согласно оценке с использованием программного пакета SRIM [7], составляло порядка 1.4. Поликристалличность распыляемых пленок не учитывалась. Контроль получаемых структур осуществлялся с помощью сканирующей ионной микроскопии в режиме регистрации вторичных электронов с использование детектора Эверхарта-Торнли. Для устранения артефактов, вызванных накоплением электрического заряда в сапфировой подложке, применялась компенсация заряда облучением расфокусированным пучком электронов с энергией $500 \mathrm{eV}$ после окончания каждой строки сканирования.

В результате распыления были получены „канавки“, определяющие длину МПТ $L$ и в среднем равные $9 \pm 5$, $19 \pm 6$ и $29 \pm 8 \mathrm{~nm}$ для номинальных ширин облучаемых полос 5,15 и $25 \mathrm{~nm}$ соответственно. Увеличение размера $L$ по сравнению с размерами облучаемой области может быть обусловлено как конечными размерами ионного пучка, связанными с неточностью фокусировки, так и рассеянием ионов в распыляемом материале. Изучение канавок показало, что разброс по $L$ и неровные края канавок обусловлены, по-видимому, также различной скоростью распыления зерен разной ориентации, которые можно было, в частности, наблюдать внутри наиболее широкой канавки. Более того, в процессе травления мы не могли контролировать степень удаления $\mathrm{Al}$, что явилось дополнительной причиной значительного разброса параметров исследованных структур. В связи с этим в настоящее время не были проведены систематические исследования зависимостей параметров МПТ от длины $L$ и ширины $w$. Ниже будут описаны результаты исследования мостика переменной толщины шириной $w=20 \mu \mathrm{m}$ и длиной $L=20 \mathrm{~nm}$. В отдельных $\mathrm{SN}$ мостиках верхний слой не удалялся и эти структуры использовались как контрольные. Измерение зависимостей от температуры (рис. 5) критических токов SN мостика $I_{c \mathrm{Al} / \mathrm{NbN}}(T)$ и МПТ $I_{c \mathrm{VTB}}(T)$ показало, что при 


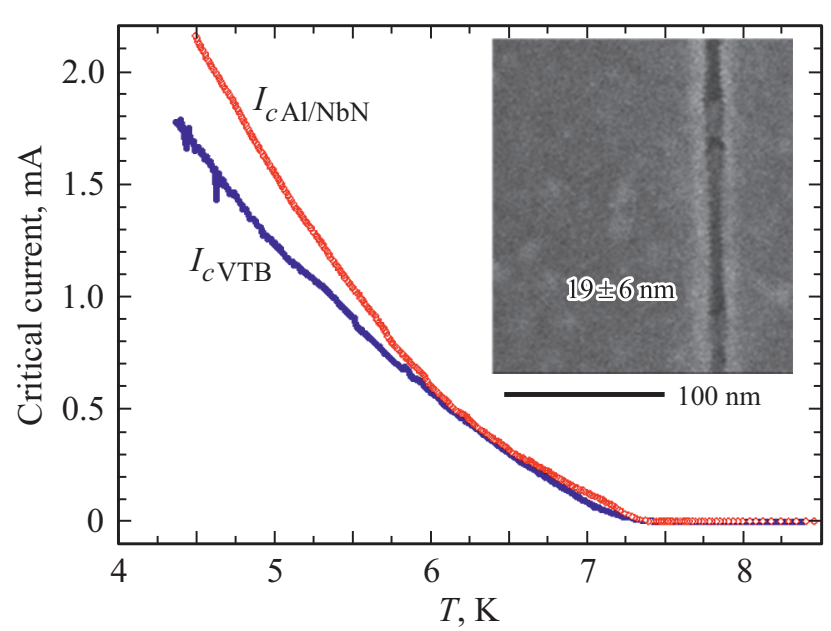

Pис. 5. Температурная зависимость критических токов мостика из бислоя $I_{c \mathrm{Al} / \mathrm{NbN}}$ и мостика переменной толщины $I_{c \text { VTB }}$ шириной $w=20 \mu \mathrm{m}$, длиной $L \approx 20 \mathrm{~nm}$.

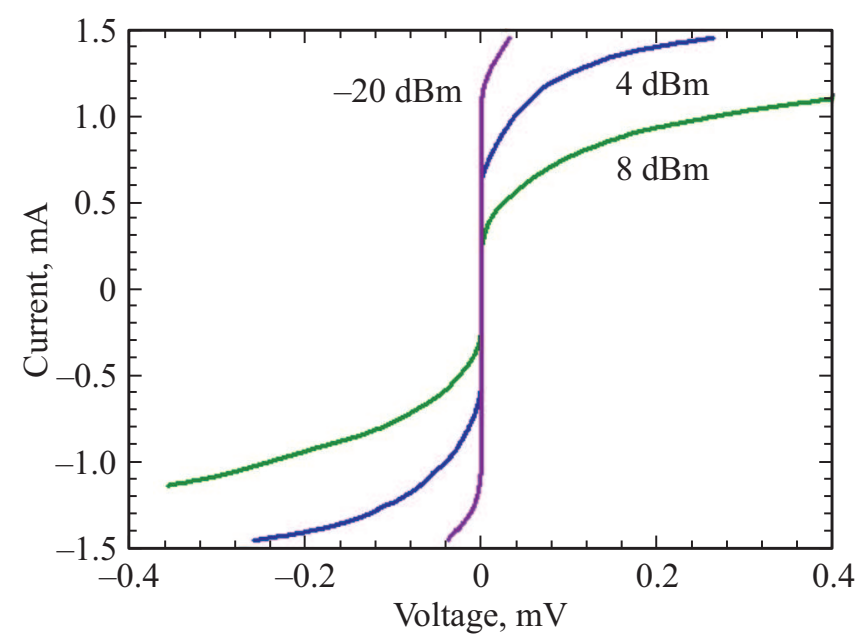

Рис. 6. Изменение BAX SN мостика шириной $w=20 \mu \mathrm{m}$ при температуре $5.5 \mathrm{~K}$ в результате нагрева под действием СВЧ с относительной мощностью равной $-20 \mathrm{dBm}, 4 \mathrm{dBm}$ и $8 \mathrm{dBm}$.

температурах ниже $6 \mathrm{~K} \quad I_{c \text { VTB }}(T)$ становится меньше $I_{c \mathrm{Al} / \mathrm{NB}}(T)$ и реализуется одно из условий для создания джозефсоновской слабой связи.

Для доказательства существования эффекта Джозефсона мостики облучались СВЧ сигналом с частотой 11-12 GHz. При облучении сплошных SN мостиков ступени Шапиро не наблюдались при всех температурах. Было зафиксировано только изменение ВАХ в результате нагрева мостиков под действием СВЧ (рис. 6). При температуре $4.2 \mathrm{~K}$ нам также не удалось наблюдать ступени Шапиро и соответственно эффект Джозефсона в исследованных мостиках переменной толщины. Однако при незначительном повышении температуры до $5.5 \mathrm{~K}$ были зафиксированы ступени тока, показанные на рис. 7. При облучении МПТ ступени тока проявлялись при приложении небольшой мощности СВЧ. Их амплитуда осциллировала с изменением относительной мощности $P$ внешнего сигнала (рис. 8). Действительно, при $P=7.8 \mathrm{~dB}$ мы наблюдаем примерно равные по амплитуде ступени тока. Возрастание $P$ до $8.5 \mathrm{~dB}$ приводит к подавлению нечетных 1-й и 3-й ступеней тока и подрастанию 2-й ступени. С ростом $P$ до $9.5 \mathrm{~dB}$ на вольтамперной характеристике видна наиболее четко только 1-я ступень тока. Таким образом, мы можем говорить об осцилляции ступеней тока в зависимости от внешнего сигнала. Это является следствием существования эффекта Джозефсона в исследованных коротких $\left(L \approx 3 \xi_{\mathrm{NbN}}\right)$ МПТ. Упомянутое выше повышение температуры от $1.3 \mathrm{~K}$ до $5.5 \mathrm{~K}$ позволило уменьшить влияние джоулева разогрева и, соответственно, усилить джозефсоновские свойства.

Как следует из рис. 8 нормальное сопротивление $R_{\mathrm{N}}$ МПТ, определенное по наклону ВАХ при воздействии СВЧ поля, равно $R_{\mathrm{N}} \approx 0.6 \Omega$. Следовательно, при оптимальной ширине контакта $w \leq 1 \mu \mathrm{m}$ оно может легко превысить $10 \Omega$, что очень важно для высокочастотных

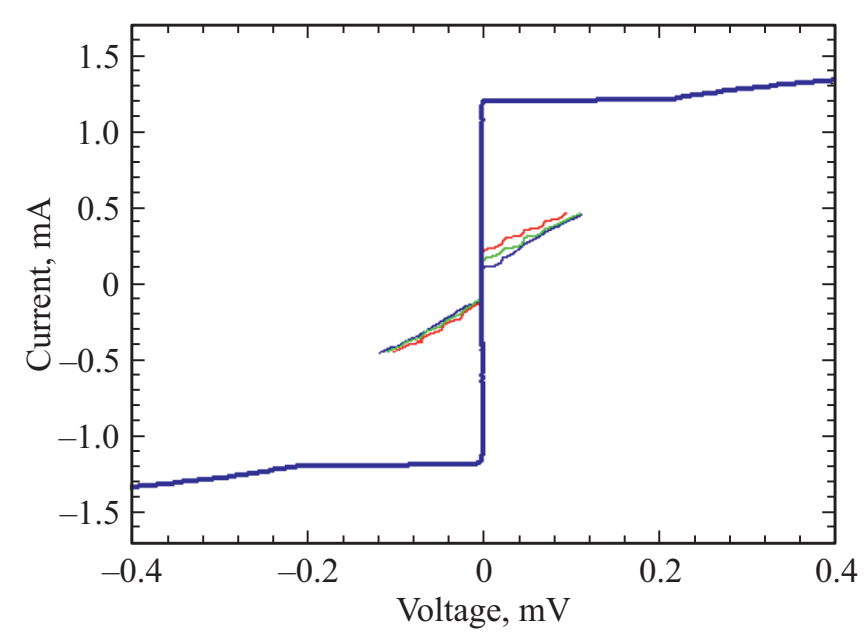

Рис. 7. BAX мостика переменной толщины в автономном режиме и при воздействии СВЧ сигнала при температуре $5.5 \mathrm{~K}$.

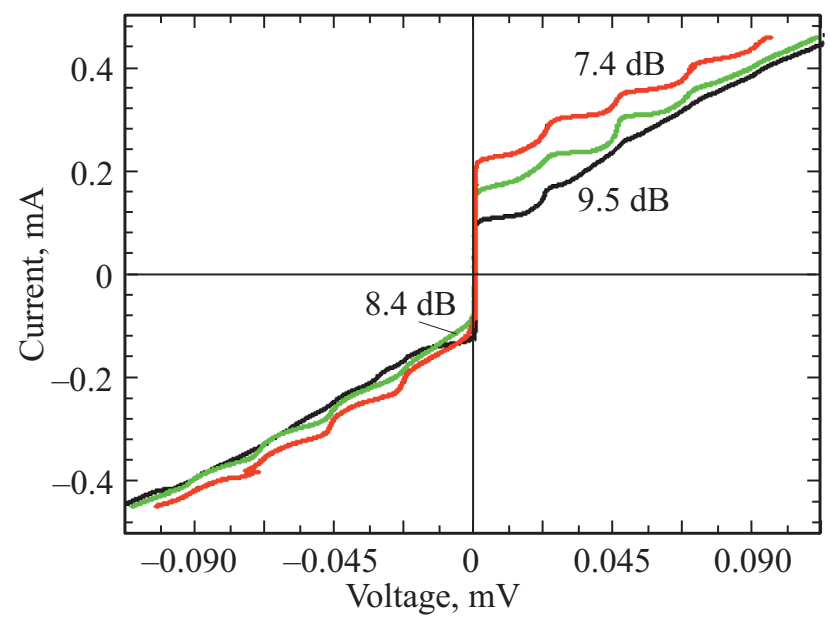

Рис. 8. ВАХ мостика переменной толщины при воздействии СВЧ сигнала при температуре $5.5 \mathrm{~K}$. 


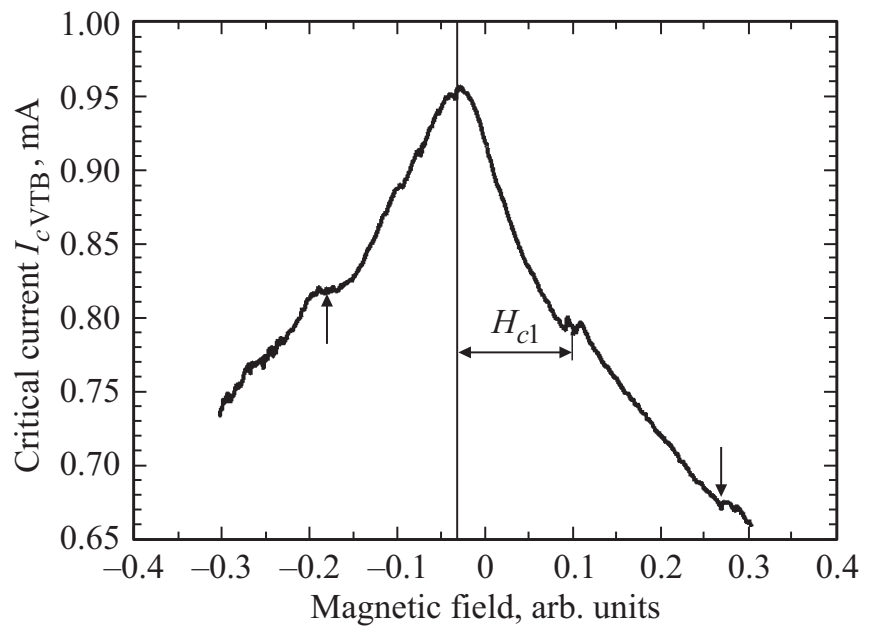

Рис. 9. Зависимость критического тока мостика переменной толщины $I_{c}$ VTв шириной $w=20 \mu \mathrm{m}$ от магнитного поля.

применений рассматриваемых МПТ в качестве детекторов, смесителей и источников электромагнитного излучения. Учитывая, что при незначительном уменьшении $L$ критический ток МПТ может достигать $2 \mathrm{~mA}$ при $4.2 \mathrm{~K}$, можно ожидать повышения характерного напряжения таких контактов до значений $V_{c} \geq 1 \mathrm{mV}$ и соответственно характерной частоты до $500 \mathrm{GHz}$. Это открывает возможности применения исследованных МПТ в частном диапазоне до $1 \mathrm{THz}$.

Важным признаком существования эффекта Джозефсона являются осцилляции $I_{c}$ в зависимости от приложенного магнитного поля. Мы исследовали наши контакты в очень слабом магнитном поле (рис. 9). Магнитное поле, перпендикулярное плоскости контакта генерировалось небольшой катушкой с током. Зависимость $I_{c \mathrm{VTB}}(H)$ характерна для очень широких джозефсоновских контактов с $w \gg \lambda_{J}$, где $\lambda_{J}-$ джозефсоновская глубина проникновения магнитного поля. По нашим оценкам $w / \lambda_{J}>100$. Из рис. 9 видно. что с ростом тока, пропускаемого через магнитную катушку, $I_{c \mathrm{VTB}}(H)$ спадает линейно с полем до достижения некоторого критического поля $H_{c 1}$, при котором разрушается способность контакта экранировать внешнее поле и в него проникают джозефсоновские вихри [8]. Стрелками на рис. 9 отмечены точки, соответствующие проникновению джозефсоновских вихрей в контакт.

\section{4. Заключение}

Были изготовлены и исследованы бислои $\mathrm{NbN} / \mathrm{Al}$ c сильным эффектом близости. В структурах из таких слоев были созданы мостики переменной толщины типа $\mathrm{Al} / \mathrm{NbN}-\mathrm{NbN}-\mathrm{Al} / \mathrm{NbN}$, в которых наблюдался эффект Джозефсона. Одно из проявлений этого эффекта связано с наблюдением ступенек тока под действием внешнего СВЧ сигнала и осцилляциями их амплитуды с мощно- стью внешнего воздействия. Второе проявление джозефсоновского эффекта связано с зависимостью $I_{c \mathrm{VTB}}(H)$ и наблюдением на ней особенностей, вызванных разрушением мейснеровского состояния и проникновением джозефсоновского вихря в МПТ. Однако наблюдаемые ступени имели малый, по сравнению с джозефсоновской резистивной моделью [8], размах по току, а также малую глубину модуляции критического тока от магнитного поля. Оба этих факта могут свидетельствовать о сильном отличии ток-фазового соотношения в исследованных МПТ от синусоидальной зависимости [9].

\section{Благодарности}

Авторы благодарят Н.В. Рогожкину за поведение фотолитографии, ионного и плазмо-химического травления тонких пленок $\mathrm{NbN}$ и $\mathrm{Al}$ при изготовлении $\mathrm{SN}$ мостиков. Результаты получены с использованием оборудования Междисциплинарного ресурсного центра по направлению „Нанотехнологии“ Научного парка СПбГУ, а также оборудования ЦКП „Физика и технология микро- и наноструктур“.

\section{Финансирование работы}

Авторы благодарят за финансовую поддержку Российский научный фонд, грант № 15-12-10020 (исследование эффекта Джозефсона в бислоях $\mathrm{NbN}$ и $\mathrm{Al}$ ) и Программу фундаментальных исследований Президиума РАН № 12 „Фундаментальные проблемы высокотемпературной сверхпроводимости“.

\section{Конфликт интересов}

Авторы заявляют, что у них нет конфликта интересов.

\section{Список литературы}

[1] D.Yu. Vodolazov, A.Yu. Aladyshkin, E.E. Pestov, S.N. Vdovichev, S.S. Ustavshikov, M.Yu. Levichev, A.V. Putilov, P.A. Yunin, A.I. El'kinal, N.N. Bukharov, A.M. Klushin. Supercond. Sci. Technol. 31, 115004 (2018).

[2] J.H. Claassen, J.M. Byers, S. Adrian. J. Appl. Phys. 82, 3028 (1997).

[3] D. Hazra, N. Tsavdaris, S. Jebari, A. Grimm, F. Blanchet, F. Mercier, C. Chapelier, M. Hofheinz. Supercond. Sci. Technol. 29, 105011 (2016).

[4] К.К. Лихарев. ЖЭТФ 61, 1700 (1971).

[5] В.Н. Губанков, В.П. Кошелец, Г.А. Овсянников. ЖЭТФ 71, 348 (1976).

[6] R.W. Moseley, W.E. Booij, E.J. Tarte, M.G. Blamire. Appl. Phys. Lett. 75, 262 (1999).

[7] J.F. Ziegler, M.D. Ziegler, J.P. Biersack. Nucl. Instr. Meth. Phys. Res. B 268, 1818 (2010). doi: 10.1016/j.nimb.2010.02.091.

[8] К.К. Лихарев, Б.Т. Ульрих. Системы с джозефсоновскими контактами. Изд-во МГУ, М. (1978).

[9] A.A. Golubov, M.Yu. Kupriyanov, E. Ilichev. Rev. Mod. Phys. 76, 411 (2004).

Редактор Т.Н. Василевская 